\title{
Cytogenetic mapping of common bean chromosomes reveals a less compartmentalized small-genome plant species
}

\author{
Andrea Pedrosa-Harand • James Kami • \\ Paul Gepts • Valérie Geffroy • Dieter Schweizer
}

Received: 13 November 2008 / Revised and Accepted: 21 January 2009 / Published online: 28 March 2009

(C) The Author(s) 2009. This article is published with open access at Springerlink.com

\begin{abstract}
Cytogenetic maps of common bean chromosomes 3, 4 and 7 were constructed by fluorescence in-situ hybridization (FISH) of BAC and a few other genomic clones. Although all clones were selected
\end{abstract}

Electronic supplementary material The online version of this article (doi:10.1007/s10577-009-9031-4) contains

supplementary material, which is available to authorized users.

Responsible Editor: Jiming Jiang.

A. Pedrosa-Harand $\cdot$ D. Schweizer

Department of Chromosome Biology, University of Vienna,

Vienna, Austria

J. Kami $\cdot$ P. Gepts

Department of Plant Sciences/MS1,

Section of Crop and Ecosystem Sciences,

University of California,

Davis, CA, USA

\section{Geffroy}

Institut de Biotechnologie des Plantes, UMR-CNRS 8618, INRA, Université Paris Sud,

Orsay, France

D. Schweizer

GMI - Gregor Mendel Institute of Molecular Plant Biology, Austrian Academy of Sciences,

Vienna, Austria

Present Address:

A. Pedrosa-Harand $(\bowtie)$

Laboratory of Plant Cytogenetics, Department of Botany,

Federal University of Pernambuco,

Recife, PE, Brazil 50670-420

e-mail: andrea.pedrosaharand@pesquisador.cnpq.br with genetically mapped markers, mostly with singlecopy RFLPs, a large subset of BACs, from 13 different genomic regions, contained repetitive sequences, as concluded from the regional distribution patterns of multiple FISH signals on chromosomes: pericentromeric, subtelomeric and dispersed. Pericentromeric repeats were present in all 11 chromosome pairs with different intensities, whereas subtelomeric repeats were present in several chromosome ends, but with different signal intensities depending on the BAC, suggesting that the terminal heterochromatin fraction of this species may be composed of different repeats. The correlation of genetic and physical distances along the three studied chromosomes was obtained for 23 clones. This correlation suggests suppression of recombination around extended pericentromeric regions in a similar way to that previously reported for plant species with larger genomes. These results indicate that a relatively small plant genome may also possess a large proportion of repeats interspersed with single-copy sequences in regions other than the pericentromeric heterochromatin and, nevertheless, exhibit lower recombination around the pericentromeric fraction of the genome.

Keywords fluorescence in-situ hybridization (FISH) . bacterial artificial chromosome (BAC) - cytogenetic map - recombination - Fabaceae 


\section{Abbreviations}

${ }^{32} \mathrm{P} \quad$ radioactive isotope of phosphorus

APA loci family of seed proteins consisting of $\alpha$-amylase inhibitors ( $\alpha-\mathrm{AI})$, phytohaemagglutinins (PHA) and arcelins (ARL)

BAC bacterial artificial chromosome Bng (common) bean genomic plasmid clone

$C_{0} t \quad C_{0}$ is the initial concentration of single stranded DNA in mol/l; $t$ is the reannealing time in seconds CCD charge-coupled device

CIAT International Center for Tropical Agriculture

cM centimorgan

Cy3-dUTP 5-aminopropargyl-2'-deoxyuridine 5 '-triphosphate coupled to red cyanine fluorescent dye

DAPI 4',6-diamidino-2-phenylindole

DNA deoxyribonucleic acid

FISH fluorescence in-situ hybridization

HindIII restriction enzyme from

Haemophilus influenzae

PCR polymerase chain reaction

RFLP restriction fragment length polymorphism

SD standard deviation

SDS sodium dodecyl sulfate

SSC saline-sodium citrate buffer

(20× SSC: $3 \mathrm{M} \mathrm{NaCl}, 0.3 \mathrm{M}$

sodium citrate, $\mathrm{pH} 7.0$ )

SSPE saline-sodium phosphate-EDTA buffer $(20 \times$ SSPE: $3 \mathrm{M}$ sodium chloride, $0.2 \mathrm{M}$ sodium hydrogenphosphate, $0.02 \mathrm{M}$ EDTA, $\mathrm{pH}$ 7.4)

TAC transformation-competent artificial chromosome

\section{Introduction}

The common bean (Phaseolus vulgaris L.) is the major legume crop for direct consumption, and is an important source of dietary proteins for populations in Africa and Latin America. In an effort to accelerate improvement of the common bean, the Phaseomics consortium has been established, bringing together bean researchers from different fields. One of the aims of this consortium is to develop genomic resources for the species (Broughton et al. 2003). A physical map for the common bean was also considered to be a priority among researchers from the legume community and should be established by 2011 (Gepts et al. 2005). Recently, a draft physical map of $P$. vulgaris cv. G19833 was developed, with 34264 clones assembled into 1183 contigs and the remaining 6385 clones existing as singletons (Schlueter et al. 2008).

To date, several genetic maps are available for the common bean (Gepts et al. 2008). This is a diploid species with 22 chromosomes and a haploid genome size estimated to be around $600 \mathrm{Mb}$ (Arumuganathan and Earle 1991; Bennett and Leitch 1995). Linkage groups from previously developed genetic maps (Vallejos et al. 1992; Freyre et al. 1998) have been assigned to the corresponding chromosome pairs by pooling RFLP markers from each linkage group and hybridizing them in situ to chromosomes (Pedrosa et al. 2003). This study provided a set of markers that allowed the identification of each chromosome of the species. It also revealed a lack of correlation between chromosome and linkage group sizes. However, the differences in recombination frequencies among and along chromosomes could not be investigated because linkage groups and chromosomes were not connected by multiple shared sequences: only one probe, composed of several RFLP markers of the same linkage group, was available for most chromosomes.

Large-insert BAC clones have frequently been used in fluorescence in-situ hybridization (FISH) experiments to physically map single-copy, genomic sequences to chromosomes of plants with a small genome size, such as Arabidopsis (Fransz et al. 2000), rice (Cheng et al. 2001a,b), sorghum (Kim et al. 2005a,b), Medicago truncatula (Kulikova et al. 2001) and Lotus japonicus (Pedrosa et al. 2002). Since several BAC clones have been selected using genetically mapped markers and mapped by FISH along chromosomes, genetic and physical distances could be compared and associated with chromosome landmarks such as centromeres, telomeres and heterochromatin. In the present work, we established cytogenetic maps based on fluorescence in-situ hybridization of BACs and a few other genomic clones for the first three common bean chromosomes. These maps enabled the evaluation of recombination frequencies along these chromosomes, gave an 
overview of the common bean genome organization and provided anchoring points for future contig maps.

\section{Materials and methods}

Plant material

Seeds from the $P$. vulgaris Mesoamerican breeding line BAT93 were obtained from the germplasm bank of the International Center for Tropical Agriculture CIAT, Cali, Colombia.

\section{Chromosome preparation}

Root tips obtained from germinating seeds were pre-treated in $2 \mathrm{mM}$ 8-hydroxyquinoline for $5 \mathrm{~h}$ at $16^{\circ} \mathrm{C}$, fixed in ethanol-acetic acid $3: 1(\mathrm{v} / \mathrm{v})$ and stored in fixative at $-20^{\circ} \mathrm{C}$ for up to several weeks. Mitotic chromosome preparation was performed as described in Pedrosa-Harand et al. (2006), with maceration in $3 \%(\mathrm{w} / \mathrm{v})$ cellulase 'Onozuka R-10' (Serva, Heidelberg, Germany) plus 30\% (v/v) pectinase (Sigma-Aldrich, St. Louis, MO, USA) in $0.01 \mathrm{M}$ citric acid-sodium citrate buffer $\mathrm{pH} 4.8$ for $1.5 \mathrm{~h}$ at $37^{\circ} \mathrm{C}$. In order to confirm the orientation of clones mapped to the short arm of chromosome 7 , young flower buds were fixed as described above for pachytene chromosome preparation. Pachytene chromosome spreads were prepared according to Armstrong et al. (2001), except that whole flower buds were digested in $0.33 \%(\mathrm{w} / \mathrm{v})$ cellulase 'Onozuka R-10' (Serva) and $0.33 \%(\mathrm{w} / \mathrm{v})$ pectolyase (Sigma-Aldrich) for $3 \mathrm{~h}$ at $37^{\circ} \mathrm{C}$, and meiocytes were left in $60 \%$ acetic acid at $45^{\circ} \mathrm{C}$ for a few seconds before re-fixation.

DNA probes

BAC clones were selected by screening high-density BAC filters from a BAT93 HindIII genomic library (Kami et al. 2006) using genetically mapped markers. BACs corresponding to the Phaseolin and APA loci were selected by Kami et al. (2006). BACs corresponding to RFLP clones (Bngs) mapped to linkage groups A, B and C (Vallejos et al. 1992) were selected using PCR fragments amplified as described in Pedrosa et al. (2003). The PCR products were purified by ethanol precipitation and labelled with ${ }^{32} \mathrm{P}$ using the random primer method. The labelled probe was purified in a Sephadex G-50 column (Sambrook et al. 1989). Filters were hybridized for $16 \mathrm{~h}$ at $65^{\circ} \mathrm{C}$ in $7.5 \%$ SDS, $5 \times$ SSPE and washed with $2 \times \mathrm{SSC}$ $0.1 \%$ SDS, $1 \times$ SSC $-0.1 \%$ SDS, $0.5 \times$ SSC- $0.1 \%$ SDS and $0.1 \times \mathrm{SSC}-0.1 \%$ SDS at $65^{\circ} \mathrm{C}$. Radioactivity signals were detected using a FX Molecular Imager (BioRad, Hercules, CA, USA). Each probe was individually hybridized to one filter and was used for a second hybridization only if no positive clone was identified in the first trial. Bacteriophages colocalized at the end of linkage group B4 with a complex disease resistance gene cluster (Geffroy et al. 2008, 2009) were selected as described by FerrierCana et al. (2003). BAC and bacteriophage DNA were isolated using the Plasmid Mini Kit (Qiagen, Hilden, Germany) and Nucleobond AX columns (Macherey-Nagel, Düren, Germany), respectively, following the manufacturer's instructions. All selected genomic clones were labelled by nick translation (Roche Diagnostics, Indianapolis, IN, USA) with Cy3-dUTP (GE Healthcare, Bucks, UK) or SpectrumGreen-dUTP (Vysis, Des Plaines, IL, USA).

\section{DNA dot blot analysis}

DNA (10 ng) from BAC clones that showed strong positive signals after library screening was spotted onto an $\mathrm{N}+$ Hybond membrane. Hybridization of the $C_{0} t-1$ fraction, isolated according to Zwick et al. (1997), was performed with the ECF random priming labelling and signal amplification system (GE Healthcare) according to the manufacturer's instructions. Fluorescent signals were detected using an FX Molecular Imager with an external laser of $488 \mathrm{~nm}$ and ECF settings (BioRad).

\section{Fluorescence In-Situ Hybridization (FISH)}

Slides were selected and pre-treated as described in Pedrosa et al. (2001). Chromosome and probe denaturation, post-hybridization washes and detection were performed according to Heslop-Harrison et al. (1991), except for the stringent wash, which was performed with $0.1 \times \mathrm{SSC}$ at $42^{\circ} \mathrm{C}$. Hybridization mixes consisted of: $50 \%(\mathrm{v} / \mathrm{v})$ formamide, $10 \%$ $(\mathrm{w} / \mathrm{v})$ dextran sulfate, $2 \times \mathrm{SSC}$ and $2-5 \mathrm{ng} / \mu \mathrm{l}$ probe. $P$. vulgaris $C_{0} t-1$ or $C_{0} t-100$ fractions were added in 5 to 100 -fold excess to the hybridization mix to block repetitive sequences where necessary. The 
mitotic and meiotic preparations were denatured for $5 \mathrm{~min}$ at $75^{\circ} \mathrm{C}$ and $3 \mathrm{~min}$ at $73^{\circ} \mathrm{C}$, respectively. All slides were hybridized for up to three days at $37^{\circ} \mathrm{C}$. Preparations were counterstained and mounted with $2 \mu \mathrm{g} / \mathrm{ml}$ DAPI in Vectashield (Vector, Burlingame, CA, USA). Re-probing of slides for localization of different DNA sequences on the same cell was performed according to Heslop-Harrison et al. (1992), up to five times.

\section{Data analysis}

Photographs were taken on a Zeiss Axioplan (Carl Zeiss) microscope equipped with a mono cool view CCD camera (Photometrics, Tucson, AZ, USA) and the IPLab spectrum software (IPLab, Fairfax, VA, USA). The ten best mitotic metaphases bearing clear hybridization signals were selected in order to calculate the position of each clone by measuring the distance of the centre of the signal(s) to the closest telomere and the total chromosome length in arbitrary units. Relative clone position was represented by the mean value of all measurements, with 0 representing the telomere of the short arm and 1 the telomere of the long arm. Relative chromosome size and arm ratio were calculated based on measurements of at least five mitotic metaphases. All measurements were performed using the 'analyse - measure length' function of the IPLab software. Assignment of a clone to a specific chromosome arm was confirmed by re-probing the slides with a previously mapped clone. Chromosomes were named and oriented according to the standard common bean nomenclature (Freyre et al. 1998; Pedrosa-Harand et al. 2008). Images were superimposed using the same software and artificial colours and imported into Adobe Photoshop version 8 for final processing.

\section{Results}

DNA markers from the Florida linkage map of the common bean (Vallejos et al. 1992) were chosen for screening the 'BAT93' BAC library (Kami et al. 2006) because its RFLP markers (Bng clones) are widely available and this was one of the three maps integrated into the core map of the species (Freyre et al. 1998). A total of 16,8 and 17 markers from linkage groups A, B and C, respectively, were used for the BAC library screening. These groups correspond to linkage groups B7, B4 and B3, respectively, of the core map (Freyre et al. 1998). The aim was to select at least 10 BAC clones for each linkage group, except for linkage group B, which had only 8 RFLP markers mapped. However, BACs corresponding to only 8, 6 and 9 markers, respectively, were identified, suggesting a lower coverage of the library for some genomic regions. BAC clones for two additional genomic regions, the Phaseolin locus from linkage group A and the APA locus from linkage group B, were previously selected (Kami et al. 2006) and also localized by FISH (Table 1).

A high proportion of the selected BACs with single-copy markers (BACs for 13 out of 25 genomic regions) did not show unique, localized signals in just one chromosome pair, as expected. Instead, three general patterns of labelling the chromosome complement were observed, suggesting the presence of repetitive sequences within their inserts. Indeed, dot blot hybridization of BAC DNA on a membrane and $C_{0} t-1$ repetitive fraction of $P$. vulgaris DNA as a probe showed stronger hybridization for those BACs than for BACs that showed unique signals after FISH (Table 1). The most common, distinct in-situ hybridization patterns were designated as subtelomeric (labelling of chromosome ends) and pericentromeric (labelling around centromeric regions) (Fig. 1a, b). In a few FISH experiments, a C-banding-like staining of the chromosomes was observed with DAPI. The detected terminal blocks corresponded to the strongest subtelomeric signals (see Supplementary Fig. S1a-d). Positive bands were also observed in centromeric regions of most chromosomes, but these bands were smaller than the pericentromeric signals observed with pericentromeric BAC clones (Supplementary Fig. S1a, e-f). This suggests that the pericentromeric BACs label beyond the pericentromeric heterochromatin. A similar hybridization pattern was observed for all BACs showing a pericentromeric pattern, although they have been selected with five different mapped markers. All BACs labelled all chromosomes of the complement, but chromosomes showed different labelling intensities. The three chromosome pairs showing the weakest hybridization signals were submetacentric and acrocentric in morphology. For the four subtelomeric BACs, three subtypes of hybridization pattern were observed. They labelled a subset of chromosome arms only and the intensity of 
Table 1 List of mapped markers and genes used for screening BAC clones and the general pattern of hybridization of the selected BACs after dot blot and FISH

\begin{tabular}{|c|c|c|c|c|c|}
\hline $\begin{array}{l}\text { Linkage } \\
\text { group }\end{array}$ & Marker/gene & BAC clone & Dot blot ${ }^{\mathrm{a}, \mathrm{b}}$ & $\begin{array}{l}\text { FISH pattern without blocking } \\
\text { DNA }^{\text {a }}\end{array}$ & $\begin{array}{l}\text { FISH pattern with blocking } \\
\text { DNA }^{\text {a }}\end{array}$ \\
\hline \multirow[t]{17}{*}{$\mathbf{A}$} & \multirow[t]{2}{*}{ Bng 23} & $20 \mathrm{~F} 21$ & NA & NA & NA \\
\hline & & $33 \mathrm{M} 20$ & +++ & Unique + weakly scattered & Unique $\left(5 \times C_{0} t-1\right)$ \\
\hline & \multirow[t]{2}{*}{ Bng 28} & $12 \mathrm{M} 3$ & +++ & Pericentromeric & NA \\
\hline & & $22 \mathrm{I} 21$ & + & Unique & Unique $\left(50 \times C_{0} t-100\right)$ \\
\hline & \multirow[t]{4}{*}{ Bng 42} & $193 \mathrm{~F} 10$ & - & Unique & Unique $\left(5 \times C_{0} t-1\right)$ \\
\hline & & 200B23 & ++ & NA & NA \\
\hline & & $202 \mathrm{~F} 18$ & + & NA & NA \\
\hline & & 215P4 & - & NA & NA \\
\hline & Bng 47 & $267 \mathrm{~K} 20$ & NA & Unique & NA \\
\hline & Bng 60 & 144D16 & + & Unique & Unique $\left(5 \times C_{0} t-1\right)$ \\
\hline & Bng 170 & $200 \mathrm{E} 15$ & +++ & Pericentromeric & Pericentromeric $\left(50 \times C_{0} t-100\right)$ \\
\hline & Bng 191 & $86 \mathrm{I} 17$ & +++ & Subterminal & Subterminal $\left(50 \times C_{0} t-100\right)$ \\
\hline & \multirow[t]{3}{*}{ Bng 204} & 111019 & NA & Disperse & NA \\
\hline & & $122 \mathrm{D} 11$ & +++ & NA & Unique $\left(100 \times C_{0} t-1\right)$ \\
\hline & & $125 \mathrm{P} 11$ & NA & Disperse & NA \\
\hline & \multirow[t]{2}{*}{ Phs } & $101 \mathrm{~J} 20$ & +++ & NA & NA \\
\hline & & $105 \mathrm{O} 5$ & +++ & Pericentromeric & Pericentromeric $\left(75 \times C_{0} t-1\right)$ \\
\hline \multirow[t]{26}{*}{ B } & \multirow[t]{8}{*}{ Bng 13} & $25 \mathrm{C} 4$ & NA & NA & NA \\
\hline & & $26 \mathrm{~A} 21$ & NA & NA & NA \\
\hline & & $26 \mathrm{~B} 20$ & + & Unique + weakly scattered & Unique $\left(20 \times C_{0} t-1\right)$ \\
\hline & & $30 \mathrm{E} 20$ & + & NA & NA \\
\hline & & $31 \mathrm{~N} 7$ & ++ & NA & NA \\
\hline & & $35 \mathrm{~K} 5$ & NA & NA & NA \\
\hline & & $38 \mathrm{C} 19$ & NA & NA & NA \\
\hline & & $47 \mathrm{~A} 5$ & NA & NA & NA \\
\hline & \multirow[t]{4}{*}{ Bng 55} & $53 \mathrm{G} 1$ & +++ & Pericentromeric & Pericentromeric $\left(50 \times C_{0} t-100\right)$ \\
\hline & & $77 \mathrm{~B} 3$ & +++ & Pericentromeric & Pericentromeric $\left(50 \times C_{0} t-1\right)$ \\
\hline & & $92 \mathrm{~B} 6$ & NA & NA & NA \\
\hline & & $92 \mathrm{P} 15$ & NA & NA & NA \\
\hline & Bng 103 & $162 \mathrm{~K} 15$ & + & Unique + weakly scattered & Unique $\left(20 \times C_{0} t-1\right)$ \\
\hline & Bng 151 & $221 \mathrm{~J} 10$ & +++ & Subterminal & Unique $\left(50 \times C_{0} t-100\right)$ \\
\hline & \multirow[t]{8}{*}{ Bng 160} & $53 \mathrm{~N} 15$ & NA & NA & NA \\
\hline & & $75 \mathrm{~K} 8$ & NA & NA & NA \\
\hline & & $75 \mathrm{H} 11$ & NA & NA & NA \\
\hline & & $86 \mathrm{~B} 17$ & NA & NA & NA \\
\hline & & $76 \mathrm{~N} 21$ & +++ & NA & NA \\
\hline & & 78L24 & +++ & Subterminal & Subterminal $\left(50 \times C_{0} t-100\right)$ \\
\hline & & $93 \mathrm{~F} 6$ & +++ & NA & NA \\
\hline & & $94 \mathrm{~F} 8$ & NA & NA & NA \\
\hline & \multirow[t]{3}{*}{ Bng 184} & $165 \mathrm{P} 21$ & NA & NA & NA \\
\hline & & $187 \mathrm{E} 12$ & +++ & NA & NA \\
\hline & & $190 \mathrm{C} 15$ & ++ & Subterminal & Unique $\left(50 \times C_{0} t-1\right)$ \\
\hline & $A P A$ & $86 \mathrm{~K} 9$ & + & Unique & NA \\
\hline
\end{tabular}


Table 1 (continued)

\begin{tabular}{|c|c|c|c|c|c|}
\hline $\begin{array}{l}\text { Linkage } \\
\text { group }\end{array}$ & Marker/gene & BAC clone & Dot blot ${ }^{\mathrm{a}, \mathrm{b}}$ & $\begin{array}{l}\text { FISH pattern without blocking } \\
\text { DNA }^{\text {a }}\end{array}$ & $\begin{array}{l}\text { FISH pattern with blocking } \\
\text { DNA }^{\text {a }}\end{array}$ \\
\hline & & 214L14 & +++ & NA & NA \\
\hline \multirow[t]{22}{*}{$\mathbf{C}$} & Bng 3 & $60 \mathrm{H} 5$ & NA & NA & NA \\
\hline & & $72 \mathrm{D} 12$ & NA & NA & NA \\
\hline & & $77 \mathrm{~J} 14$ & + & Disperse & Unique $\left(50 \times C_{0} t-100\right)$ \\
\hline & & 92D1 & + & NA & NA \\
\hline & Bng 12 & 142D9 & + & Unique & NA \\
\hline & Bng 16 & $253 \mathrm{~F} 1$ & ++ & NA & NA \\
\hline & & $267 \mathrm{H} 4$ & + & Disperse & Unique $\left(50 \times C_{0} t-100\right)$ \\
\hline & & 284P11 & NA & NA & NA \\
\hline & & $285 \mathrm{~J} 8$ & NA & NA & NA \\
\hline & Bng 33 & $95 \mathrm{~L} 13$ & + & Unique & NA \\
\hline & & $174 \mathrm{E} 13$ & + & Unique & NA \\
\hline & Bng 63 & $287 \mathrm{I} 5$ & +++ & Pericentromeric & NA \\
\hline & Bng 75 & 199D13 & + & Unique + weakly scattered & Unique $\left(50 \times C_{0} t-100\right)$ \\
\hline & & $220 \mathrm{C} 15$ & + & NA & NA \\
\hline & & $230 \mathrm{M} 3$ & NA & NA & NA \\
\hline & & $234 \mathrm{H} 24$ & NA & NA & NA \\
\hline & Bng 106 & $147 \mathrm{~K} 17$ & + & Unique & NA \\
\hline & & $165 \mathrm{~K} 4$ & NA & NA & NA \\
\hline & & 173L21 & + & NA & NA \\
\hline & & 180D23 & NA & NA & NA \\
\hline & Bng 114 & $116 \mathrm{H} 6$ & ++ & Disperse & Unique $\left(50 \times C_{0} t-100\right)$ \\
\hline & Bng 124 & $91 \mathrm{~K} 16$ & + & Unique & NA \\
\hline
\end{tabular}

${ }^{\mathrm{a}} \mathrm{NA}$, not analysed.

${ }^{\mathrm{b}}$ Intensity of signals: +++ , strong; ++ , medium; +, weak; -, very weak or not detected.

the labelling at different chromosome ends varied depending on the BAC clone used (Supplementary Fig. S1b-d). Five BACs, from four different genomic regions, showed a more dispersed labelling of the complement, sometimes showing stronger signals in proximal chromosome regions (closer to centromeres than to telomeres). Those BACs, as well as two subtelomeric ones (BACs 190C15 and 221J10), could be mapped after addition of blocking DNA in the hybridization mix. Blocking DNA was also added when a unique signal could be discerned but a weaker, scattered labelling of the complement was also observed (Table 1).

A total of 23 clones (19 BACs, three bacteriophages and one plasmid clone) showed unique and localized signals on chromosomes with or without the addition of blocking DNA. These clones were mapped on mitotic metaphase chromo- somes because at this stage chromosomes reach the maximum degree of condensation and it is expected that both euchromatin and heterochromatin are similarly condensed, allowing a more precise positioning of clones along the chromosome length. Pachytene chromosomes offer a higher mapping resolution, but positioning of clones along the chromosome is influenced by its heterochromatin content and degree of condensation. Furthermore, as was observed in the common bean, the chromosome pairs observed at pachytene stage may be entangled, hampering the measurement of each chromosome from one end to the other and, thus, the estimation of the relative position of each clone. The 23 clones were mapped to three chromosomes pairs, which were named 3,4 and 7 according to the nomenclature of the corresponding linkage groups proposed by Freyre et al. (1998) and defined 
Fig. 1 In-situ hybridization of genetically assigned clones on $P$. vulgaris BAT93 mitotic (a-e) and pachytene (f) chromosomes. (a) 78L24 (red). (b) 77B3 (red). (c) BACs mapped on chromosome 3: 147K17 (red), 267H4 (pink), 199D13 (yellow) and 91K16 (green). (d) Clones mapped on chromosome 4: B35 (yellow), 26B20 (red), $162 \mathrm{~K} 15$ (green) and 86K9 (pink). (e) Clones mapped on chromosome 7: 193F10 (green), 144D16, Phaseolin and 267K20 (simultaneously in red) and 33M20 (yellow). (f) Higher resolution mapping of 193F10 (green), 144D16 (yellow) and Phaseolin (red). All chromosomes were counterstained with DAPI and visualized in blue, except in (f) were they are seen in grey. Bar in (f) represents $2.5 \mu \mathrm{m}$
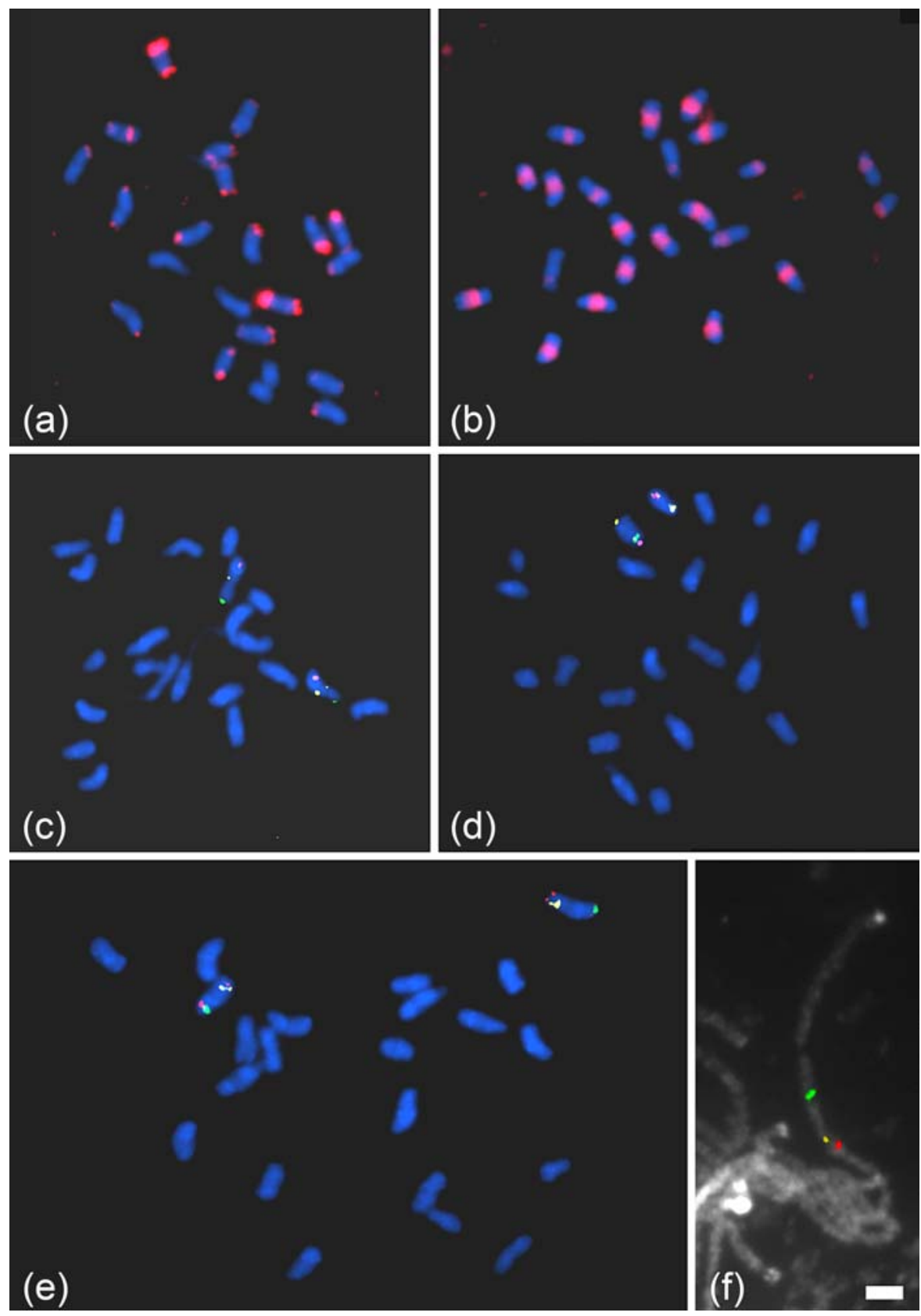

as the standard nomenclature for common bean chromosomes (Pedrosa-Harand et al. 2008). Chromosomes 3, 4 and 7 were metacentric, with arm ratios of $1.85,1.47$ and 1.69 , respectively. Chromosome 7 was the largest, with chromosomes 3 and 4 having relative lengths of 0.97 and 0.86 compared to chromosome 7 .

BACs corresponding to eight mapped markers were included in the cytogenetic map of chromosome 3 (Figs. 1c, 2 and 3, and Table 2). Four of these BACs were mapped with the help of $C_{0} t-1$ or $C_{0} t-100$ blocking DNA from $P$. vulgaris. Three BACs mapped to the short arm and five to the long arm of this chromosome. The centromere was located between BACs 267H4 (Bng16) and 199D13 (Bng75). The genetic distance between these two markers was $6.3 \mathrm{cM}(6.66 \%$ of the total linkage group length of $94.6 \mathrm{cM})$, but the physical distance between the respective BAC clones corresponded to one-third of 


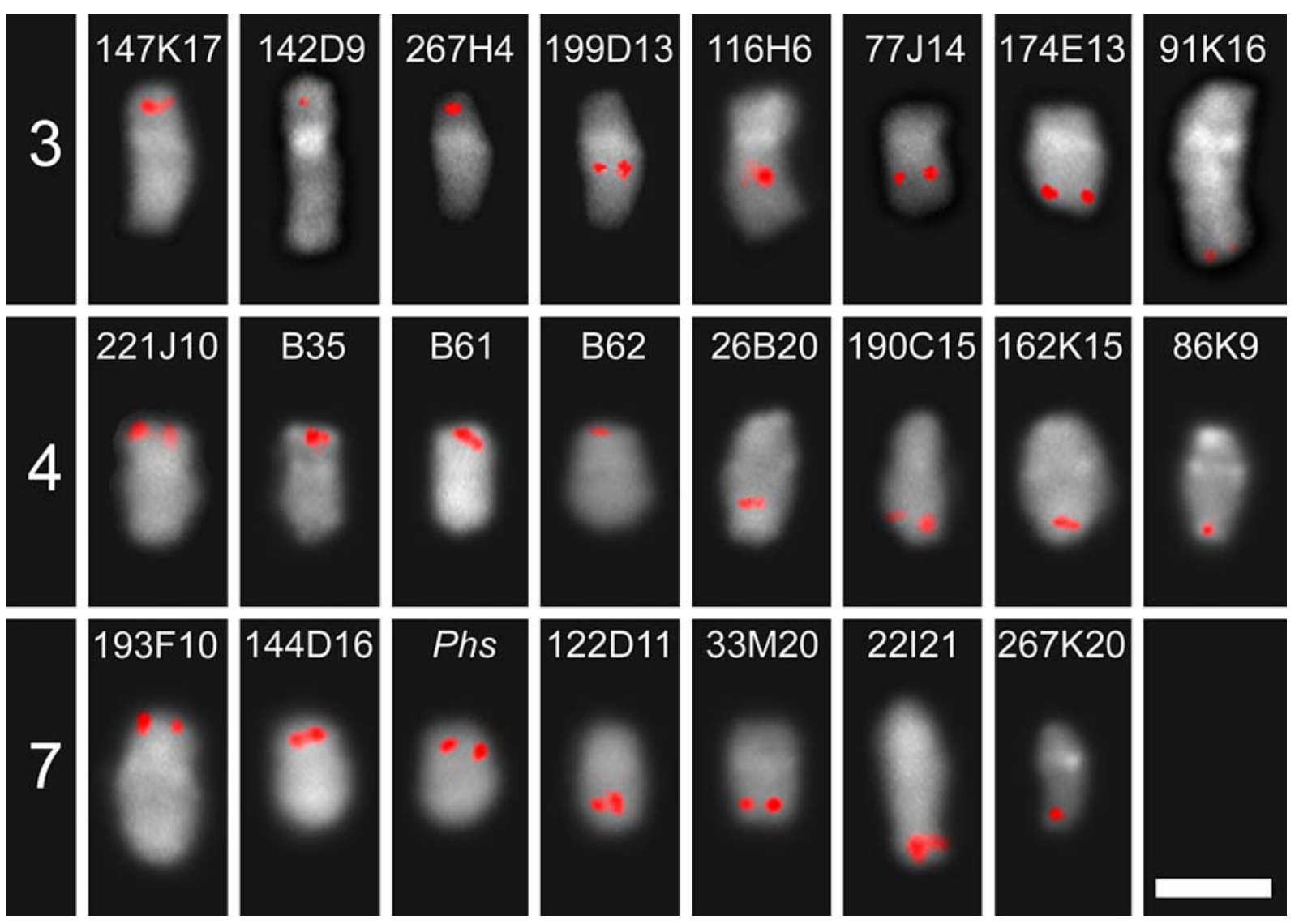

Fig. 2 Localization of clones (red signals) on P. vulgaris BAT93 mitotic chromosomes (grey). One chromosome is shown for each mapped clone. Clones are ordered according to the chromosomes they belong to and to their position in the cytogenetic map. Bar represents $2.5 \mu \mathrm{m}$

strongest signals on the short and long arms of chromosome 4. Two other subtelomeric BACs from this chromosome (190C15 and 221J10) also labelled the subtelomeric region of more than one chromosome pair, but the number of subtelomeres labelled, as well as the relative intensity of signals among chromosome ends, were different among these three BACs. These differences in hybridization pattern suggest the presence of different subtelomeric repeats in the common bean genome.

The map of chromosome 7 includes six BACs and a clustered, low-copy-number, gene family (Phaseolin), which was mapped with a plasmid that contains one copy of this gene. The Phaseolin clone and two BACs were placed on the short arm and four BACs were mapped to the long arm (Fig. 1e, 2 and 3, and Table 2). Higher-resolution mapping of the short arm of chromosome 7 was performed on pachytene chromosomes (Fig. 1f) and confirmed the position of 
Chromosome 3

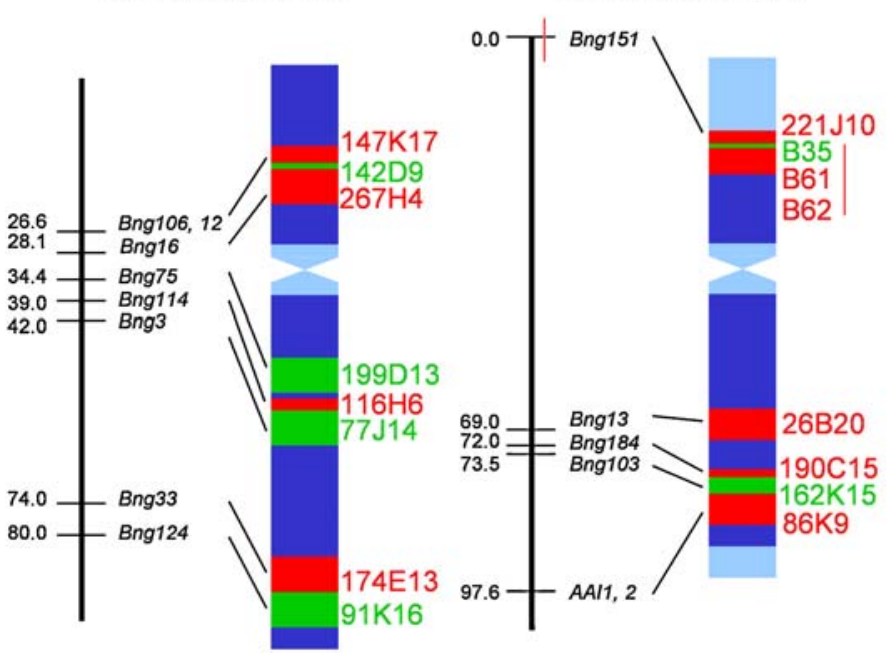

Chromosome 7

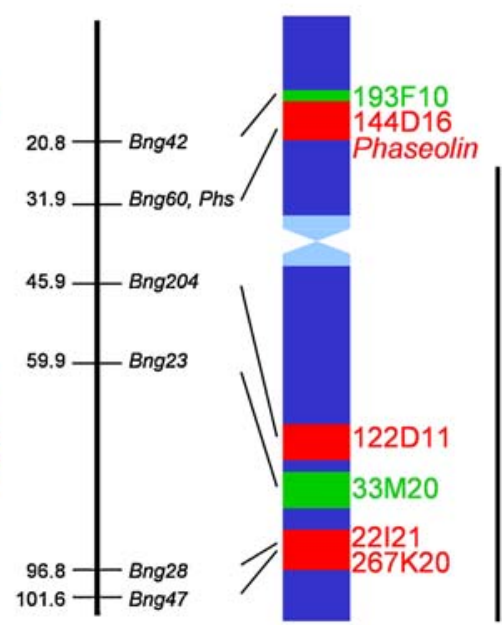

Fig. 3 Diagrammatic representation of chromosome 3, 4 and 7 cytogenetic maps (right) and genetic position of the corresponding molecular markers (left). Clones are indicated in red and green, and chromosomes in blue. Light blue blocks represent approximate location of constitutive heterochromatin as visualized as brighter-stained regions on mitotic chromosomes after FISH experiments. Chromosomes and linkage

the corresponding clones measured from mitotic chromosomes (Table 2). Again, a suppression of recombination around the pericentromeric region was observed: half of the chromosome (around the centromere) is represented by less than $15 \%$ of the linkage group length.

\section{Discussion}

In the present work, we have cytogenetically mapped common bean chromosomes 3, 4 and 7 using BACs and other genomic clones through FISH. The established maps reveal important features of the common bean chromosomes, such as suppression of recombination around extended pericentromeric regions and the frequent presence of repetitive sequences interspersed with single-copy sequences in pericentromeric, interstitial and subtelomeric regions.

All BAC clones used in the present work were selected with single-copy, genetically mapped markers. Nevertheless, selected BACs for more than half of the markers used showed a repetitive pattern of hybridization after FISH, indicating the presence of interspersed repeats associated with single-copy sequences within the BAC insert. Dot blot hybridiza- groups are drawn to scale, respectively. Positions of genetic markers in $\mathrm{cM}$ are derived from the map of Vallejos et al. (1992). All three linkage groups were rotated top to bottom with respect to the original map to better represent the correspondence of markers to the short and long chromosome arms. Bar on the right represents $2.5 \mu \mathrm{m}$

tion was an efficient strategy for selecting BACs containing lower amount of repetitive DNA, especially when more than one BAC clone was available for the same, or closely mapped, genetic markers. Southern blot hybridization has been used for the same purpose (Kim et al. 2005b), but requires BAC DNA digestion, electrophoresis and blotting. Other alternatives may be selection of BACs with high gene content (Kim et al. 2005a), selection of BACs corresponding to markers from regions of high genetic recombination (Wang et al. 2007), and subcloning of BACs followed by selection of subclones devoid of major repetitive DNA sequences (Pedrosa et al. 2002; Janda et al. 2006).

When no other BAC was available for the same genetic position, BACs containing repetitive sequences were used as a probe and blocking DNA was added to the hybridization mix in different proportions to suppress the hybridization of the repetitive sequences, leaving unique signals from the singlecopy part of the insert. Only 6 of the 11 tested BACs could be successfully mapped after addition of blocking DNA, mainly those originally showing a less intense, more dispersed signal. None of the BACs showing a pericentromeric distribution could be cytologically mapped, possibly because of the high 
Table 2 Genetic locations of markers and physical locations of their associated BACs on the respective linkage groups and mitotic metaphase chromosomes

\begin{tabular}{|c|c|c|c|c|c|}
\hline \multicolumn{2}{|c|}{ Genetic map } & \multicolumn{4}{|l|}{ Physical map } \\
\hline Marker & Position $^{a}$ & Clone & Mean & $n$ & $\mathrm{SD}^{\mathrm{b}}$ \\
\hline \multicolumn{6}{|c|}{ Chromosome 3/C } \\
\hline Bng 106 & 0.28 & BAC $147 \mathrm{~K} 17$ & 0.17 & 28 & 0.04 \\
\hline Bng 12 & 0.28 & BAC 142D9 & 0.20 & 27 & 0.04 \\
\hline Bng 16 & 0.30 & BAC $267 \mathrm{H} 4$ & 0.21 & 20 & 0.05 \\
\hline Bng 75 & 0.36 & BAC 199D13 & 0.53 & 28 & 0.05 \\
\hline Bng 114 & 0.41 & BAC $116 \mathrm{H} 6$ & 0.60 & 24 & 0.04 \\
\hline Bng 3 & 0.44 & BAC 77J14 & 0.62 & 24 & 0.04 \\
\hline Bng 33 & 0.78 & BAC 174E13 & 0.87 & 29 & 0.06 \\
\hline Bng 124 & 0.85 & BAC $91 \mathrm{~K} 16$ & 0.93 & 23 & 0.04 \\
\hline \multicolumn{6}{|c|}{ Chromosome 4/B } \\
\hline Bng 151 & 0.00 & BAC $221 \mathrm{~J} 10$ & 0.13 & 27 & 0.04 \\
\hline- & - & $\mathrm{B} 35^{\mathrm{c}}$ & 0.14 & 33 & 0.05 \\
\hline- & - & $\mathrm{B} 61^{\mathrm{c}}$ & 0.18 & 32 & 0.07 \\
\hline- & - & $\mathrm{B} 62^{\mathrm{c}}$ & 0.19 & 34 & 0.07 \\
\hline Bng 13 & 0.66 & BAC $26 \mathrm{~B} 20$ & 0.70 & 21 & 0.06 \\
\hline Bng 184 & 0.69 & BAC 190C15 & 0.82 & 26 & 0.05 \\
\hline Bng 103 & 0.71 & BAC $162 \mathrm{~K} 15$ & 0.83 & 26 & 0.06 \\
\hline APA & 0.94 & BAC $86 \mathrm{~K} 9$ & 0.87 & 22 & 0.07 \\
\hline \multicolumn{6}{|c|}{ Chromosome 7/A } \\
\hline Bng 42 & 0.20 & BAC $193 F 10$ & 0.15 & 32 & 0.06 \\
\hline Bng 60 & 0.30 & BAC 144D16 & 0.17 & 39 & 0.05 \\
\hline Phaseolin & 0.30 & $\mathrm{Phs}$ & 0.18 & 34 & 0.06 \\
\hline Bng 204 & 0.44 & BAC 122D11 & 0.70 & 26 & 0.08 \\
\hline Bng 23 & 0.57 & BAC 33M20 & 0.78 & 36 & 0.05 \\
\hline Bng 28 & 0.93 & BAC 22I 21 & 0.88 & 28 & 0.05 \\
\hline Bng 47 & 0.97 & BAC $267 \mathrm{~K} 20$ & 0.88 & 26 & 0.06 \\
\hline
\end{tabular}

${ }^{\mathrm{a}}$ Position of a genetic marker in the genetic map is indicated as percentage of total linkage group length, calculated from data presented by Vallejos et al. (1992). Position in cM is indicated in Fig. 3.

${ }^{\mathrm{b}}$ Standard deviation.

${ }^{\mathrm{c}}$ See Geffroy et al. 2009.

proportion of repetitive sequences within the BAC insert or because of the too high amount of these repetitive sequences in the genome. Heterochromatic regions are indeed difficult to map by FISH due to an excess of repetitive sequences present in BACs from these regions (Kim et al. 2005b). Addition of $C_{0} t-1$ DNA may help to get single copy signals, but it is not effective in all cases (Wang et al. 2007). In potato, even 200-fold excess of blocking DNA was not enough for enabling the mapping of a few BACs tested (Dong et al. 2000).

Although those BAC clones containing a higher proportion of repetitive sequences could not be mapped, they were useful in contributing to the genomic characterization of the common bean. The high proportion of BACs selected with single copy sequences that showed a repetitive hybridization pattern suggested the presence of a high proportion of interspersed repetitive sequences in the common bean genome. Analysis of 89017 BAC-end sequences and 1404 shotgun sequences estimated that $49.2 \%$ of the common bean genome is composed of repetitive sequences, a higher proportion than estimated for other legume genomes, such as Trifolium repens or soybean (Schlueter et al. 2008). Furthermore, these results also indicated that repetitive sequences are not as compartmentalized within the common bean genome as in other plant species, such as Arabidopsis thaliana, Medicago truncatula, Sorghum bicolor and Solanum lycopersicum (Fransz et al. 1998; Kulikova et al. 2001; Kim et al. 2005a; Wang et al. 2006). In those species, repetitive sequences are present at pericentromeric heterochromatin, but euchromatic regions, encompassing the chromosome arms, are greatly devoid of repeats. In rice, although heterochromatin is mostly located in pericentromeric regions, terminal heterochromatic knobs were detected in the indica variety Zhongxian 3037 (Cheng et al. 2001a). Nevertheless, all 18 RFLP-selected BACs for chromosome 10 of rice could be mapped by FISH (Cheng et al. 2001b). The $600 \mathrm{Mbp}$ common bean genome (Arumuganathan and Earle 1991; Bennett and Leitch 1995) is only around 4 times larger than the Arabidopsis genome (125 Mbp; TAGI 2000) and 50\% larger than the rice genome (389 Mbp; IRGSP 2005). Nevertheless, it is smaller than the genomes of sorghum ( $818 \mathrm{Mbp}$; Price et al. 2005) and tomato ( $950 \mathrm{Mbp}$; Arumuganathan and Earle 1991), indicating that genome size alone cannot always successfully predict genome structure in plants. Random and TAC-end sequencing in another small-genome legume, Lotus japonicus (472 Mbp), also suggested that the gene spaces in this species are intermingled with repeated sequences (Sato et al. 2008).

The distribution patterns observed with pericentromeric and subtelomeric BACs in the present work can 
improve the heterochromatin characterization available so far for the species (Zheng et al. 1991; Moscone et al. 1999). These previous studies established the heterochromatin distribution in the common bean based on C-banding. Heterochromatin amount was estimated at $10 \%$ of the total chromosome length and heterochromatic bands were observed in centromeric and a few terminal regions (Moscone et al. 1999). Reproducibility and resolution were low, however, and it was not possible to assign heterochromatic bands to specific chromosomes. BACs that labelled pericentromeric regions, such as BAC 77B3, hybridized to pericentromeric regions at very different intensities, in agreement with the presence of heterochromatic blocks of different sizes at different chromosomes of the species. On the other hand, the presence of a subtelomeric heterochromatin in the common bean was more evident after the detection of subtelomeric signals in most chromosome ends with BACs such as 78L24, than with previous C-banding experiments. This subtelomeric heterochromatin corresponds to terminal knobs seen on pachytene chromosomes (see Fig. 1f). Furthermore, three slightly distinct subtelomeric hybridization patterns were detected with BACs 78L24, 190C15 and 221J10, suggesting the existence of at least three types of repetitive sequences composing the subtelomeric heterochromatin of the common bean. Subcloning and sequencing will be necessary to further characterize this genome fraction, as performed in wheat (Zhang et al. 2004).

High suppression of recombination, comprising at least one-third of the proximal chromosomal regions, was observed in the common bean, especially for chromosomes 3 and 7, for which a larger number of BACs was available. In species with small genomes, such as Arabidopsis and rice, a relatively uniform distribution of recombination events has been observed, with suppression of recombination restricted to a few $\mathrm{Mbp}$ around the centromeres, where most of their repetitive DNA is present (Schmidt et al. 1995; Cheng et al. 2001b). On the other hand, strong suppression of recombination comprising large proximal regions has been demonstrated in wheat (Gill et al. 1996) and barley (Künzel et al. 2000), species with large genomes (approximately $16000 \mathrm{Mbp}(2 \mathrm{n}=6 \mathrm{x})$ and $5000 \mathrm{Mbp}$, respectively (Arumuganathan and Earle 1991)). In potato (approximately $1700 \mathrm{Mbp}(2 \mathrm{n}=4 \mathrm{x})$ (Arumuganathan and Earle 1991)) and tomato, suppression of recombination was associated with the prominent pericentromeric heterochromatin (Sherman and Stack 1995; Iovene et al. 2008; Tang et al. 2008). In sorghum, a species with a genome approximately twice as large as the rice genome, heterochromatin comprises around $50 \%$ of its genome and is restricted to proximal chromosomal regions. Again, recombination was largely suppressed, approximately 34 -fold lower, in those regions compared with euchromatic regions (Kim et al. 2005a). Although the precise heterochromatineuchromatin border in the common bean has not been established, the suppression of recombination in extended pericentromeric regions was evident in this species, indicating that this phenomenon can also be observed in a plant with a relatively small and less compartmentalized genome. The cytogenetic maps of the remaining chromosomes, currently under construction, will confirm whether the suppression of recombination is present in all common bean chromosomes.

Acknowledgements We thank Alba Torres (CIAT) for providing the seeds and Dr C. Eduardo Vallejos (University of Florida) for the Bng clones. A.P-H. was partially supported by a grant from the Conselho Nacional de Desenvolvimento Científico e Tecnológico (CNPq), Brazil, and by the Hertha-Firnberg program from the Austrian Science Fund (FWF) on behalf of the Federal Ministry for Education, Science and Culture (BMBWK), Austria. The work was partially supported by the Gregor Mendel Institute of Molecular Plant Biology (GMI), Austria.

Open Access This article is distributed under the terms of the Creative Commons Attribution Noncommercial License which permits any noncommercial use, distribution, and reproduction in any medium, provided the original author(s) and source are credited.

\section{References}

Armstrong SJ, Franklin FCH, Jones GH (2001) Nucleolusassociated telomere clustering and pairing precede meiotic chromosome synapsis in Arabidopsis thaliana. J Cell Sci 114:4207-4217

Arumuganathan K, Earle ED (1991) Nuclear DNA content of some important plant species. Plant Mol Biol Rep 9:208-218

Bennett MD, Leitch I (1995) Nuclear DNA amounts in angiosperms. Ann Bot 76:113-176

Broughton WJ, Hernandez G, Blair M et al (2003) Beans (Phaseolus spp.) - model food legumes. Plant Soil 252:55-128

Cheng Z, Buell CR, Wing RA, Gu M, Jiang J (2001a) Toward a cytological characterization of the rice genome. Genet Res 11:2133-2141 
Cheng Z, Presting GG, Buell CR, Wing RA, Jiang J (2001b) High-resolution pachytene chromosome mapping of bacterial artificial chromosomes anchored by genetic markers reveals the centromere location and the distribution of genetic recombination along chromosome 10 of rice. Genetics 157:1749-1757

Dong F, Song J, Naess SK et al (2000) Development and applications of a set of chromosome-specific cytogenetic DNA markers in potato. Theor Appl Genet 101:10011007

Ferrier-Cana E, Geffroy V, Macadré C et al (2003) Characterization of expressed NBS-LRR resistance gene candidates from common bean. Theor Appl Genet 106:251-261

Fransz P, Armstrong S, Alonso-Blanco C et al (1998) Cytogenetics for the model system Arabidopsis thaliana. Plant J 13:867-876

Fransz P, Armstrong S, de Jong JH (2000) Integrated cytogenetics map of chromosome arm $4 \mathrm{~S}$ of $A$. thaliana: structural organization of heterochromatin knob and centromere region. Cell 100:367-376

Freyre R, Skroch PW, Geffroy V et al (1998) Towards an integrated linkage map of common bean. 4. Development of a core linkage map and alignment of RFLP maps. Theor Appl Genet 97:847-856

Geffroy V, Macadré C, David P et al (2009) Molecular analysis of a large subtelomeric nucleotide-binding-site-leucinerich-repeat family in two representative genotypes of the major gene pools of Phaseolus vulgaris. Genetics 181:405-419 doi:10.1534/genetics.108.093583

Geffroy V, Sevignac M, Billant P et al (2008) Resistance to Colletotrichum lindemuthianum in Phaseolus vulgaris: a case study for mapping two independent genes. Theor Appl Genet 116:407-415

Gepts P, Beavis WD, Brummer EC et al (2005) Legumes as a model plant family. Genomics for food and feed. Report of the Cross-Legume Advances through Genomics Conference. Plant Physiol 137:1228-1235

Gepts P, Aragão F, Barros E (2008) Genomics of Phaseolus beans, a major source of dietary protein and micronutrient. In: Moore PH, Ming R (eds) Genomics of Tropical Crop Plants. Springer, Berlin, pp 113-143

Gill KS, Gill BS, Endo TR, Taylort T (1996) Identification and high-density mapping of gene-rich regions in chromosome group I of wheat. Genetics 144:1883-1891

Heslop-Harrison JS, Schwarzacher T, Anamthawat-Jónsson K et al (1991) In-situ hybridization with automated chromosome denaturation. Technique 3:109-115

Heslop-Harrison JS, Harrison GE, Leitch IJ (1992) Reprobing of DNA:DNA in-situ hybridization preparations. Trends Genet 8:372-373

[IRGSP] International Rice Genome Sequencing Project (2005) The map-based sequence of the rice genome. Nature 436:793-800

Iovene M, Wielgus SM, Simon PW et al (2008) Chromatin structure and physical mapping of chromosome 6 of potato and comparative analyses with tomato. Genetics 180:1307-1317

Janda J, Safár J, Kubaláková M et al (2006) Advanced resources for plant genomics: a BAC library specific for the short arm of wheat chromosome 1B. Plant J 47:977-986
Kami J, Poncet V, Geffroy V, Gepts P (2006) Development of four phylogenetically-arrayed BAC libraries and sequence of the APA locus in Phaseolus vulgaris. Theor Appl Genet 112:987-998

Kim J-S, Islam-Faridi MN, Klein PE et al (2005a) Comprehensive molecular cytogenetic analysis of sorghum genome architecture: distribution of euchromatin, heterochromatin, genes and recombination in comparison to rice. Genetics 171:1963-1976

Kim J-S, Klein PE, Klein RR et al (2005b) Molecular cytogenetic maps of Sorghum linkage groups 2 and 8 . Genetics 169:955-965

Kulikova O, Gualtieri G, Geurts R et al (2001) Integration of the FISH pachytene and genetic maps of Medicago truncatula. Plant J 27:49-58

Künzel G, Korzun L, Meister A (2000) Cytologically integrated physical restriction fragment length polymorphism maps for the barley genome based on translocation breakpoints. Genetics 154:397-412

Moscone EA, Klein F, Lambrou M, Fuchs J, Schweizer D (1999) Quantitative karyotyping and dual-color FISH mapping of 5S and 18S-25S rDNA probes in the cultivated Phaseolus species (Leguminosae). Genome 42:1224-1233

Pedrosa A, Jantsch MF, Moscone EA, Ambros PF, Schweizer D (2001) Characterisation of pericentromeric and sticky intercalary heterochromatin in Ornithogalum longibracteatum (Hyacinthaceae). Chromosoma 110:203-213

Pedrosa A, Sandal N, Stougaard J, Schweizer D, Bachmair A (2002) Chromosomal map of the model legume Lotus japonicus. Genetics 161:1661-1672

Pedrosa A, Vallejos CE, Bachmair A, Schweizer D (2003) Integration of common bean (Phaseolus vulgaris L.) linkage and chromosomal maps. Theor Appl Genet 106:205-212

Pedrosa-Harand A, de Almeida CCS, Mosiolek M et al (2006) Extensive ribosomal DNA amplification during Andean common bean (Phaseolus vulgaris L.) evolution. Theor Appl Genet 112:924-933

Pedrosa-Harand A, Porch T, Gepts P (2008) Standard nomenclature for common bean chromosomes and linkage groups. Annu Rep Bean Improv Coop 51:106-107

Price HJ, Dillon SL, Hodnett G et al (2005) Genome evolution in the genus Sorghum (Poaceae). Ann Bot 95:219-227

Sambrook J, Fritsch EF Maniatis T (1989) Molecular Cloning: A Laboratory Manual, 2nd edn. Cold Spring Harbor Laboratory Press, New York

Sato S, Nakamura Y, Kaneko T et al (2008) Genome structure of the legume, Lotus japonicus. DNA Res 15:227-239

Schlueter JA, Goicoechea JL, Collura K et al (2008) BAC-end sequence analysis and a draft physical map of the common bean (Phaseolus vulgaris L.) genome. Tropical Plant Biol $1: 40-48$

Schmidt R, West J, Love K et al (1995) Physical map and organization of Arabidopsis thaliana chromosome 4. Science 270:480-483

Sherman JD, Stack SM (1995) Two-dimensional spreads of synaptonemal complexes from solanaceous plants, VI: High-resolution recombination nodule map for tomato (Lycopersicon esculentum). Genetics 141:683-708 
Tang X, Szinay D, Lang C et al (2008) Cross-species bacterial artificial chromosome-fluorescence in-situ hybridization painting of the tomato and potato chromosome 6 reveals undescribed chromosomal rearrangements. Genetics 180:1319-1328

[TAGI] The Arabidopsis Genome Initiative (2000) Analysis of the genome sequence of the flowering plant Arabidopsis thaliana. Nature 408:796-815

Vallejos CE, Sakiyama NS, Chase CD (1992) A molecular marker-based linkage map of Phaseolus vulgaris L. Genetics 131:733-740

Wang Y, Tang X, Cheng Z et al (2006) Euchromatin and pericentromeric heterochromatin: comparative composition in the tomato genome. Genetics 172:2529-2540
Wang K, Guo W, Zhang T (2007) Development of one set of chromosome-specific microsatellite-containing BACs and their physical mapping in Gossypium hirsutum L. Theor Appl Genet 115:675-682

Zhang P, Li W, Fellers J, Friebe B, Gill BS (2004) BAC-FISH in wheat identifies chromosome landmarks consisting of different types of transposable elements. Chromosoma 112:288-299

Zheng J, Masashi M, Uchiyama H, Morikawa H, Tanaka R (1991) Giemsa C-banding patterns in several species of Phaseolus L. and Vigna Savi, Fabaceae. Cytologia 56:459-466

Zwick MS, Hanson RE, McKnight TD (1997) A rapid procedure for isolation of $C_{0} \mathrm{t}-1$ DNA from plants. Genome 40:138-142 